\title{
Patent Foramen Ovale, Ischemic Stroke and Migraine: Systematic Review and Stratified Meta-Analysis of Association Studies
}

\author{
Daniel Davis ${ }^{\mathrm{a}}$ John Gregson ${ }^{\mathrm{a}}$ Peter Willeit ${ }^{\mathrm{a}, \mathrm{c}}$ Blossom Stephan ${ }^{\mathrm{a}}$ \\ Rustam Al-Shahi Salman ${ }^{b} \quad$ Carol Brayne ${ }^{a}$ \\ ${ }^{a}$ Department of Public Health and Primary Care, University of Cambridge, Cambridge, and ${ }^{b}$ Division of Clinical \\ Neurosciences, University of Edinburgh, Edinburgh, UK; ' Department of Neurology, Innsbruck Medical University, \\ Innsbruck, Austria
}

\section{Key Words}

Systematic review $\cdot$ Meta-analysis $\cdot$ Patent foramen ovale $\cdot$

Cryptogenic stroke $\cdot$ Migraine

\begin{abstract}
Background: Observational data have reported associations between patent foramen ovale (PFO), cryptogenic stroke and migraine. However, randomized trials of PFO closure do not demonstrate a clear benefit either because the underlying association is weaker than previously suggested or because the trials were underpowered. In order to resolve the apparent discrepancy between observational data and randomized trials, we investigated associations between (1) migraine and ischemic stroke, (2) PFO and ischemic stroke, and (3) PFO and migraine. Methods: Eligibility criteria were consistent; including all studies with specifically defined exposures and outcomes unrestricted by language. We focused on studies at lowest risk of bias by stratifying analyses based on methodological design and quantified associations using fixed-effects meta-analysis models. Results: We included 37 studies of 7,686 identified. Compared to reports in the literature as a whole, studies with population-based comparators showed weaker associations between migraine with aura and cryptogenic ischemic stroke in younger women (OR 1.4; 95\% Cl 0.9-2.0; 1 study), PFO and ischemic stroke
\end{abstract}

(HR 1.6; $95 \mathrm{Cl} 1.0-2.5 ; 2$ studies; OR 1.3; 95\% Cl 0.9-1.9; 3 studies), or PFO and migraine (OR 1.0; 95\% Cl 0.6-1.6; 1 study). It was not possible to look for interactions or effect modifiers. These results are limited by sources of bias within individual studies. Conclusions: The overall pairwise associations between PFO, cryptogenic ischemic stroke and migraine do not strongly suggest a causal role for PFO. Ongoing randomized trials of PFO closure may need larger numbers of participants to detect an overall beneficial effect.

Copyright $\odot 2012$ S. Karger AG, Base

\section{Introduction}

Modifiable risk factors for ischemic stroke may be targets for primary or secondary prevention, especially if the strength of their association suggests that they might be causal. Up to one third of ischemic strokes are 'cryptogenic' because a recognized cause is not identified [1]. One putative cause of cryptogenic ischemic stroke is paradoxical embolism through patent foramen ovale (PFO) [2], itself a consequence of failure of the septa on either side of the fetal interatrial shunt to fuse after birth. Moreover, suggested associations between PFO and migraine are of interest because migraine has also been considered a risk factor for ischemic stroke [3].

\section{KARGER}

E-Mail karger@karger.ch www.karger.com/ned

\section{(C) 2012 S. Karger AG, Basel 0251-5350/13/0401-0056\$38.00/0 \\ Karger \\ Open access \\ This is an Open Access article licensed under the terms of} the Creative Commons Attribution- NonCommercial-NoDerivs 3.0 License (www.karger.com/OA-license), applicaDerivs 3.0 License (www.karger.com/OA-license), applica-
ble to the online version of the article only. Distribution for non-commercial purposes only.
Daniel Davis

Institute of Public Health

University of Cambridge, Robinson Way

Cambridge CB2 0SR (UK)

Tel. +44 1223330 300, E-Mail dhjd2@cam.ac.uk 
Fig. 1. Diagramatic representation of systematically examined associations. Summary of relationships between pairwise associations, outlining operationalized definitions of exposures and outcomes.

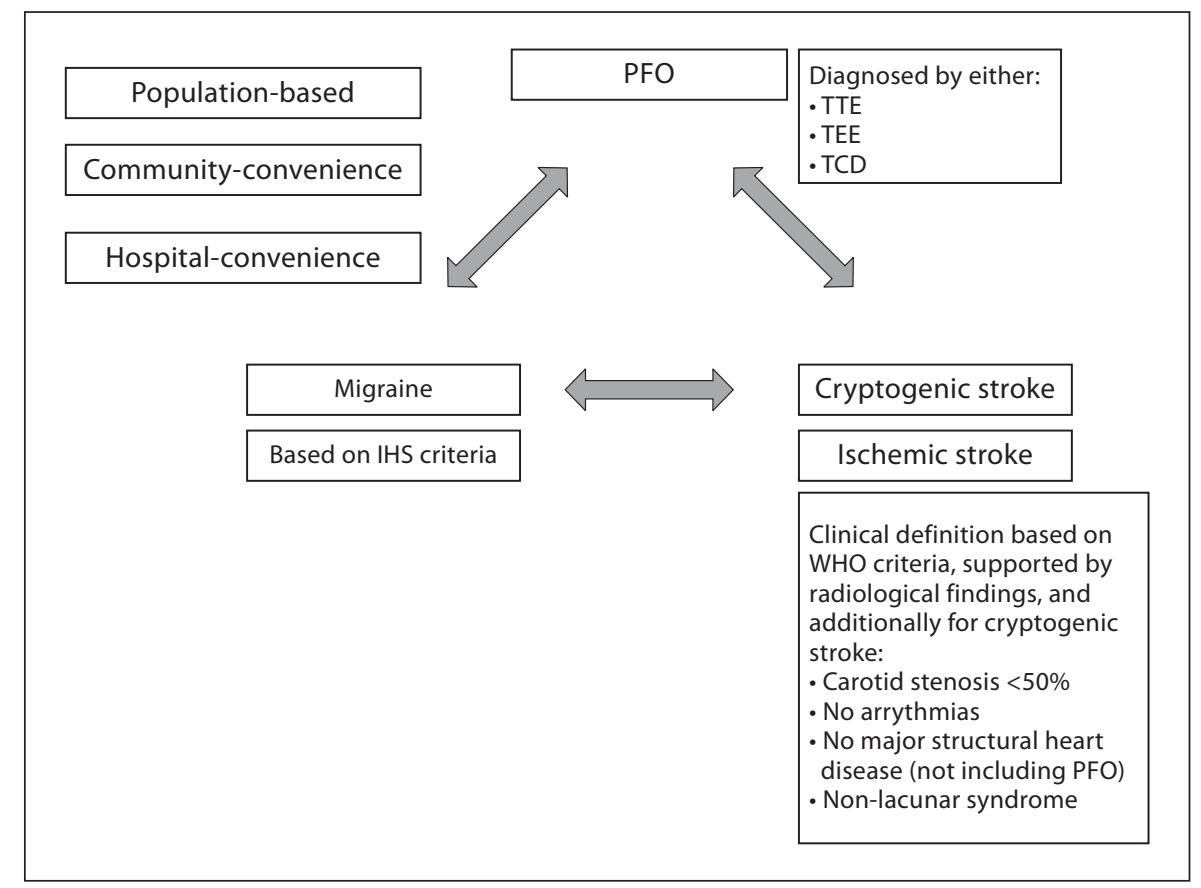

Non-blinded and non-randomized interventional studies of percutaneous PFO closure have suggested benefits of PFO closure on recurrent cryptogenic ischemic stroke [4-6] and refractory migraine [7-10], but randomized controlled trials have not confirmed these effects [11, 12]. This suggests the possibility that the reported observational data, like the uncontrolled trials, may have been biased or confounded. While the randomized trials may have been underpowered to detect a benefit of closure, this may have been driven by the original estimated effect size being based on a stronger association than is actually the case.

In this context, it is timely to review the observational studies and the way in which previous meta-analyses addressed methodological biases when pooling estimates of association. To date, systematic reviews have suggested significant associations between migraine and ischemic stroke [odds ratio (OR) 2.2; 95\% confidence intervals (CI) 1.6-3.0] [13], PFO and ischemic stroke (OR 2.9; 95\% CI 2.1-4.0) [14], and PFO and migraine (OR 2.5; 95\% CI 2.03.1) [15]. However, the degree of bias in observational data differs between studies, and not accounting for these differences may lead to propagation of these biases in the pooled estimates [16]. One approach to this issue is to stratify analyses based on methodological design, thereby reducing heterogeneity in observational studies in the meta-analysis.

Patent Foramen Ovale, Stroke and Migraine
Here, we set out to refine the interpretation of the current literature in order to (1) quantify the interrelated associations between migraine, $\mathrm{PFO}$ and stroke, and (2) to inform the design of randomized trials of PFO closure. Therefore, we undertook a series of systematic reviews and meta-analyses investigating the pairwise associations between a past history of migraine, $\mathrm{PFO}$ and the occurrence of cryptogenic ischemic stroke or all ischemic stroke (fig. 1), applying consistent eligibility criteria across all three relationships. We specifically gave priority to population-based studies, prospective cohort designs and studies that had matched or adjusted for known confounders for stroke, with a view to stratifying by study design and restricting meta-analyses to methodologically similar population sampling frames.

\section{Methods}

The protocol followed the Meta-analysis of Observational Studies in Epidemiology (MOOSE) guidelines [17] (online suppl. checklist; for all online supplementary material, see www. karger.com/doi/10.1159/000341924; study characteristics of all included studies are given in full, along with referenced PRISMA flowchart detailing excluded studies).

\section{Eligibility Criteria}

We searched for cohort, case-control or cross-sectional studies unrestricted by demographic features or language of publication, 
which had been conducted in population or hospital settings, and which compared the associations between any two relationships (fig. 1). We required studies defining ischemic stroke by WHO criteria (supported by radiological findings) and cryptogenic ischemic strokes defined as non-lacunar clinical syndromes without carotid stenosis $>50 \%$, cardiac arrhythmias or structural heart disease (excluding PFO). To be included, we required studies that did not report an outcome of cryptogenic ischemic stroke but instead report total first-ever or recurrent ischemic stroke with adjustment for known risk factors for ischemic stroke (specifically hypertension, diabetes, hypercholesterolemia, atrial fibrillation, smoking, alcohol, family history). We included studies defining migraine according to the International Headache Society (IHS) classification $[18,19]$. PFO must have been diagnosed by contrast transthoracic echocardiogram (TTE), transesophageal echocardiogram (TEE) or transcranial Doppler (TCD) ultrasound during Valsalva maneuver. Cerebral infarction in the context of complex migraine is a well-recognized clinical phenomenon, and so studies reporting migrainous infarction were not considered further. We did not include data from placebo arms of randomized trials because interventional studies are not required to use a consistent sampling frame. We excluded studies of children, pregnant women and those reporting associations within family pedigrees.

\section{Information Sources}

D.D. searched Medline from 1950 on PubMed, Embase from 1980 on NHS Evidence Health Information Resources, and Science Citation Index on Web of Science from 1950, all to April 2012. We sought journal publications as well as conference abstracts and contacted authors of abstracts to determine whether further data had been published. In addition, the bibliographies of included articles and other systematic reviews were screened.

\section{Search Terms and Study Selection}

D.D. used comprehensive textword and Medical Subject Heading $(\mathrm{MeSH})$ to find relevant studies in humans (full search terms given in MOOSE checklist, online suppl. material). Four reviewers (D.D., J.G., P.W., B.S.) independently screened articles by title and abstract after de-duplication through first author surname, title and first page number with those for full-text review, and subsequent inclusion agreed by consensus. We sought every publication relating to each included study using a search strategy based on the full name of the study or its acronym, as well as forward searching using citation index databases.

\section{Data Extraction}

Two reviewers independently extracted study data using standardized forms developed after piloting and critically appraised each study using the Newcastle-Ottawa scale (NOS) [20]. The NOS assesses population selection, comparability of cases and controls, and adequacy of outcome assessment (including outcome ascertainment and attrition). In keeping with the MOOSE guidelines, we did not use the NOS to determine study inclusion but to guide the classification of studies by similarities in design.

We classified a hierarchy of population sampling methods from lowest to highest risk of bias (online suppl. table S1), where 'population-based' refers to a sampling frame including all subgroups within a geographical population, unrestricted by demographic or clinical features, 'community-convenience' indicates selection from outpatient participants, and 'hospital-conve- nience' denotes participants recruited only from hospital inpatients. We considered cryptogenic ischemic stroke and ischemic stroke as separate outcomes.

Data Analysis

J.G. and P.W. conducted the statistical analyses using STATA version 10.1. Where multiple estimates of association were reported, the most adjusted estimate was used in analyses. Summary statistics for hazard ratios (HR), relative risks (RR) or OR and their accompanying 95\% CI were calculated using a MantelHaenszel fixed-effect model. Statistical heterogeneity was assessed with the $\mathrm{I}^{2}$ statistic.

\section{Results}

We identified 7,686 studies (online suppl. MOOSE checklist). We reviewed the full text of 116 studies, and excluded studies are fully referenced in the PRISMA flow diagrams (online suppl. fig. S1-S3). Supplementary table S2 gives further details of any study considered in any previous systematic reviews and meta-analyses, if any such study was excluded here. Finally, we included 37 studies in this review. We have separately summarized study characteristics, their results (and their meta-analysis, where appropriate) and risk of bias according to the association being investigated. Full details of all reviewed studies are given in online supplementary tables S3-S5. Table 1 shows the characteristics of only those included studies with either population-based sampling frames or a prospective design.

\section{Migraine and Ischemic Stroke}

We identified one prospective and one populationbased case-control study of women with migraine with aura with conflicting results (fig. 2).

Prospective Studies. The Women's Health Study (WHS), which included 27,840 female health care professionals aged $>45$ years, was the only prospective study in this section to meet all inclusion criteria [21]. The most fully adjusted model estimated an association with ischemic stroke (HR 1.2; 95\% CI 0.9-1.7 for migraine and HR 1.9; 95\% CI 1.2-3.1 for active migraine with aura).

Population-Based Case-Control Studies. One casecontrol study used a population-based sampling frame [22]. In women aged 15-49 years, 192 participants with migraine with aura were not associated with cryptogenic stroke (adjusted OR 1.4; 95\% CI 0.9-2.0). In a small subgroup of these women with known PFO, there was no evidence of a different association (adjusted OR 2.1; 95\% CI $0.8-5.3 ; \mathrm{n}=21$ ) compared to the group known to not have PFO (adjusted OR 1.5; 95\% CI 1.0-2.2; $\mathrm{n}=142$ ). 
Table 1. Characteristics of included population-based and prospective studies

\begin{tabular}{|c|c|c|c|c|c|c|c|c|}
\hline $\begin{array}{l}\text { First } \\
\text { author } \\
\text { year }\end{array}$ & Design & $\begin{array}{l}\text { Follow- } \\
\text { up } \\
\text { years }\end{array}$ & $\begin{array}{l}\text { Age } \\
\text { (SD) } \\
\text { years }\end{array}$ & Population & Exposure & Outcome & Confounders & $\begin{array}{l}\text { Method of } \\
\text { addressing } \\
\text { confounding }\end{array}$ \\
\hline $\begin{array}{l}\text { Kurth, } \\
2006 \text { [21] }\end{array}$ & Cohort & 10 & $\begin{array}{l}55 \\
(7.5)\end{array}$ & $\begin{array}{l}\text { Female health } \\
\text { professionals }\end{array}$ & $\begin{array}{l}\text { IHS } \\
\text { structured } \\
\text { interview }\end{array}$ & $\begin{array}{l}\text { Ischemic stroke } \\
\text { adjusted for } \\
\text { known RF }\end{array}$ & $\begin{array}{l}\text { Age, HTN, DM, chol, } \\
\text { smoking, BMI, EtOH, } \\
\text { menopause, HRT, HTN meds, } \\
\text { chol meds, OCP, FHx MI }\end{array}$ & Cox regression \\
\hline
\end{tabular}

\section{PFO-stroke}

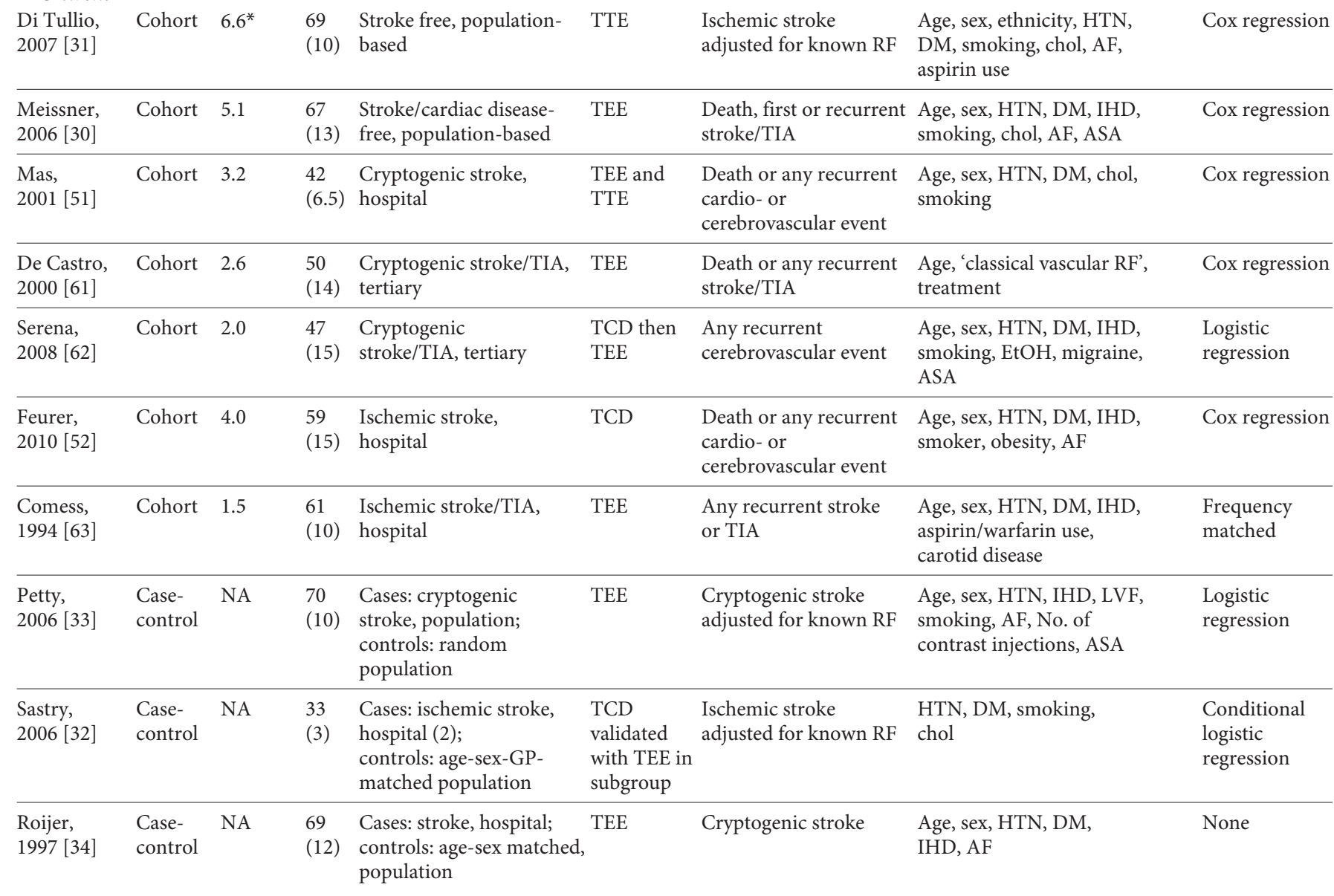

\section{PFO-migraine}

Rundek, Cross- NA 69 Cases: stroke-free cohort, TTE

2008 [45] sectional (10) population-based;

controls: cross-sectional

$\begin{array}{ll}\text { Age, sex, ethnicity, HTN, } & \text { Logistic } \\ \text { DM, chol, smoking } & \text { regression }\end{array}$

HTN = Hypertension; DM = diabetes mellitus; IHD = ischemic heart disease; $\mathrm{LVF}=$ left ventricular failure; $\mathrm{chol}=$ hypercholesterolemia; $\mathrm{OCP}=$ oral contraceptive pill; ASA $=$ atrial septal aneurysm; TIA $=$ transient is chemic attack; meds = medications; $\mathrm{EtOH}=$ alcohol intake; FHx MI = family history of myocardial infarction; HRT $=$ hormone replacement thera- py; $\mathrm{AF}=$ atrial fibrillation; $\mathrm{RF}=$ risk factor; $\mathrm{MA}=$ migraine with aura. ${ }^{*}$ Only mean follow-up reported.

Only prospective studies and/or population-based studies are presented here. Full characteristics of all considered studies are given in suppl. tables 3-5. 


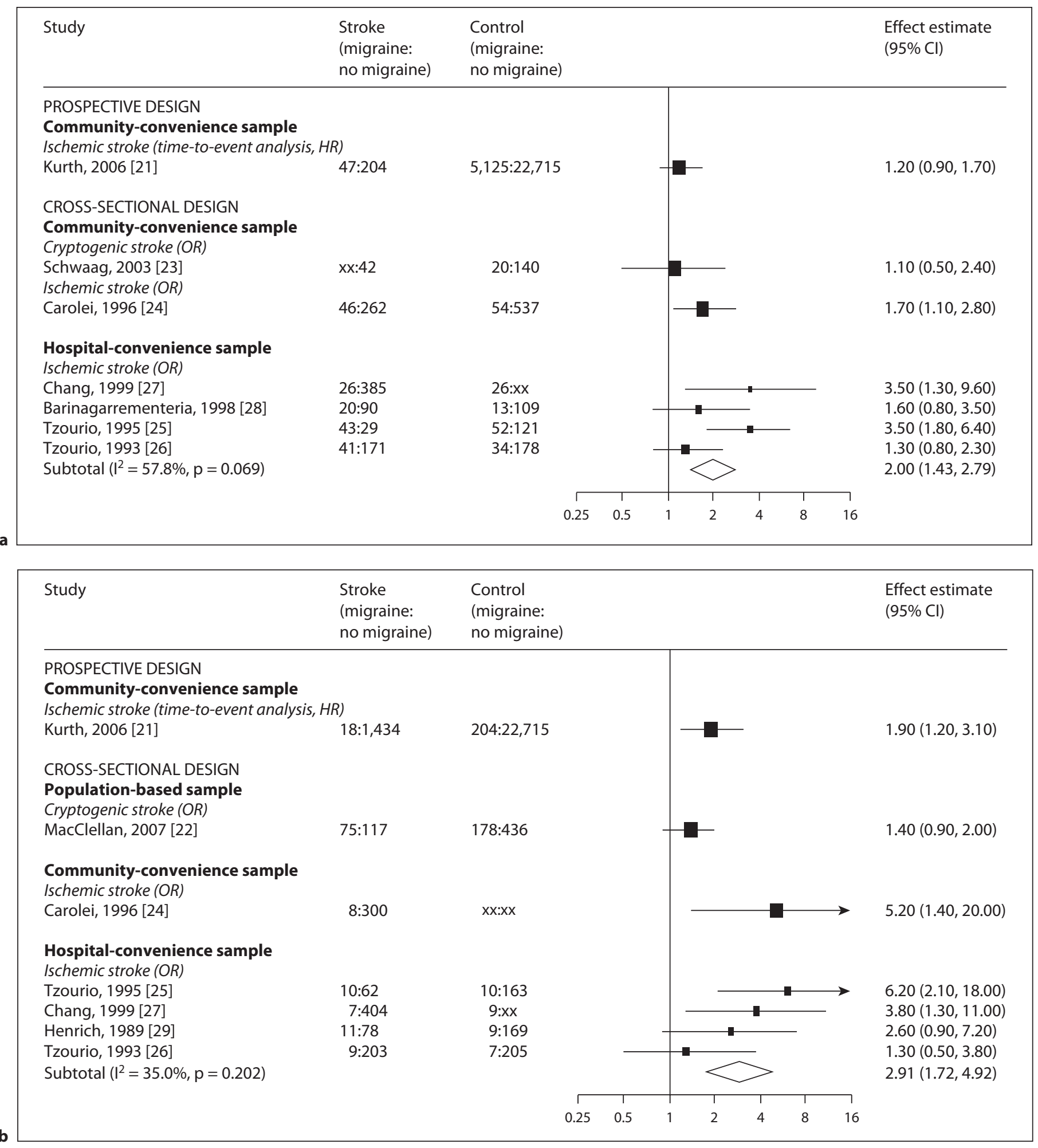

Fig. 2. a Meta-analysis of the reported associations between migraine and ischemic stroke (by study design and sampling frame). b Meta-analysis of the reported associations between migraine with aura and ischemic stroke (by study design and sampling frame). Forest plot showing results of meta-analysis. Studies are grouped by design and sampling frame. Black squares are proportional to the study size, lines represent $95 \%$ confidence intervals. The open diamond summarizes the pooled estimate within each stratum. Absolute values are given for cases and controls (numerator and denominator), $\mathrm{xx}$ indicates where these were not reported. 
Non-Population-Based Case-Control Studies. Figure 4a shows the estimated associations for any history of migraine and ischemic stroke, stratified by study design. The reported association of one study comparing cryptogenic stroke cases with community-convenience controls (OR 1.1; 95\% CI 0.5-2.4) [23] was somewhat weaker than the association in a study comparing ischemic stroke cases [24] with community-convenience controls (OR 1.7; 95\% CI 1.1-2.8) than the pooled risk estimate of studies of ischemic stroke with hospital-convenience controls [25-28] (pooled OR 2.0; 95\% CI 1.4-2.8; $\mathrm{I}^{2}=58 \%$ ). Figure $2 \mathrm{~b}$ shows the meta-analysis of studies reporting migraine with aura subtypes [25-27, 29]. This yielded a pooled OR of 2.9 and $95 \%$ CI of $1.7-4.9\left(\mathrm{I}^{2}=35 \%\right)$. Failure to account for atrial fibrillation was a feature common to all these studies.

\section{PFO and Ischemic Stroke}

Pooled results from prospective and population-based studies did not demonstrate an association between PFO and ischemic stroke (fig. 3).

Population-Based Prospective Studies. We identified 2 population-based cohort studies in essentially strokefree populations where ischemic stroke adjusted for known vascular risk factors was the main outcome (fig. 3) [30, 31]. The pooled HR for risk of primary ischemic stroke in relation to PFO was 1.6 with $95 \%$ CI of $1.0-2.5\left(\mathrm{I}^{2}=0 \%\right)$. The other prospective studies reported no statistically significant association (where $\mathrm{p}<0.05$ ), either individually or if pooled (OR 1.0; 95\% CI 0.6-1.8; $\mathrm{I}^{2}=0 \%$ ) (fig. 3).

Population-Based Case-Control Studies. Three studies compared cryptogenic ischemic stroke with healthy controls sampled from the general population, yielding a pooled OR of 1.3 and $95 \%$ CI of $0.9-1.8\left(\mathrm{I}^{2}=0 \%\right.$ ) (fig. 3 ) [32-34]. Two studies performed subgroup analyses to assess the association of larger shunts with stroke [32, 33]. Pooling the association across studies yielded an OR of 1.3 and $95 \%$ CI of $0.8-2.1\left(\mathrm{I}^{2}=79 \%\right)$.

Non-Population-Based Case-Control and Cross-Sectional Studies. A total of 10 studies compared cryptogenic ischemic stroke with: (1) healthy community-convenience controls [35, 36]; (2) controls undergoing echocardiography for non-stroke indications [37-39], or (3) ischemic stroke of known cause, adjusted for other vascular risk factors [40-44]. When subdivided by a population sampling frame, the pooled ORs for communityconvenience and hospital-convenience controls were 1.9 (95\% CI 1.2-3.1; $\left.\mathrm{I}^{2}=39 \%\right)$ and $2.8\left(95 \%\right.$ CI $2.1-3.6 ; \mathrm{I}^{2}=$ 27\%), respectively (fig. 3).

Patent Foramen Ovale, Stroke and Migraine
PFO and Migraine

We found one population-based study, and this did not show an association between PFO and migraine (fig. 4).

Cross-Sectional and Case-Control Studies. In addition to the stroke outcomes above, the population-based NOMAS study [45] reported the association between PFO and migraine as OR of 1.0 (95\% CI 0.6-1.6), and this was not different when only considering migraine with aura (OR 1.0; 95\% CI 0.7-1.7). Garg et al. [46] reported no association with PFO (OR 1.0; 95\% CI 0.6-1.7) in 144 strokefree migraineurs recruited from a tertiary clinic who were compared to age- and sex-matched controls selected from a register of healthy volunteers. The other case-control study used convenience controls, and the estimate for any history of migraine and PFO was OR of 3.9 (95\% CI 1.4-11) (fig. 4) [47]. Two further abstracts were identified that reported population-based associations, and full publication of both studies is awaited [48, 49].

\section{Discussion}

\section{Summary of Evidence}

For each pairwise association between migraine, $\mathrm{PFO}$ and ischemic stroke, there is inconsistent evidence, and the strength of the reported associations is dependent on study design. Overall, associations apparent in case-control studies were not evident in the more generalizable population-based studies with sufficiently valid assessments of exposure and outcome.

Migraine and Ischemic Stroke. In the subset of younger women with migraine with aura and cryptogenic stroke, there is no clear association [22], and there are no studies with a strict population-based sampling frame describing this relationship in men (of any age). However, there is some evidence from a prospective study suggesting an association in female health workers aged $>45$ years with migraine with aura and ischemic stroke [21], though atrial fibrillation was not accounted for despite a separate report demonstrating an association between this and stroke [50].

PFO and Ischemic Stroke. Cohort studies did not demonstrate an association between PFO and first-ever [30, 31] or recurrent ischemic stroke risk [51, 52], findings which are supported by three case-control studies comparing PFO in cryptogenic ischemic stroke with population-based controls [32-34].

PFO and Migraine. The only population-based study investigating the association between $\mathrm{PFO}$ and migraine with or without aura was cross-sectional and found no association [45].

Neuroepidemiology 2013;40:56-67 


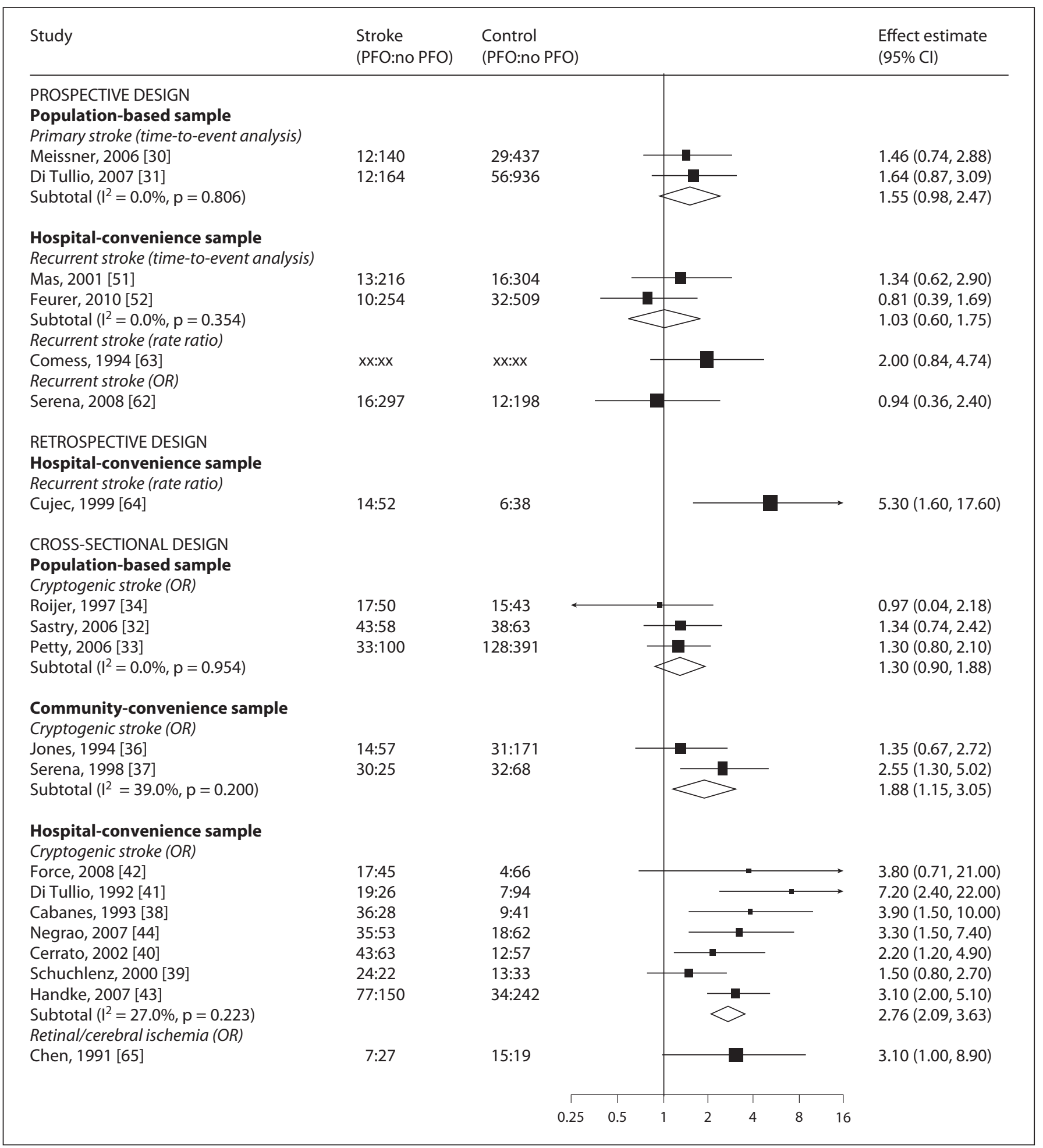

Fig. 3. Meta-analysis of the reported associations between PFO and ischemic stroke (by study design and sampling frame). Forest plot showing results of meta-analysis. Studies are grouped by design and sampling frame. Black squares are proportional to the study size, lines represent $95 \%$ confidence intervals. The open diamond summarizes the pooled estimate within each stratum. Absolute values are given for cases and controls (numerator and denominator), $\mathrm{xx}$ indicates where these were not reported. 


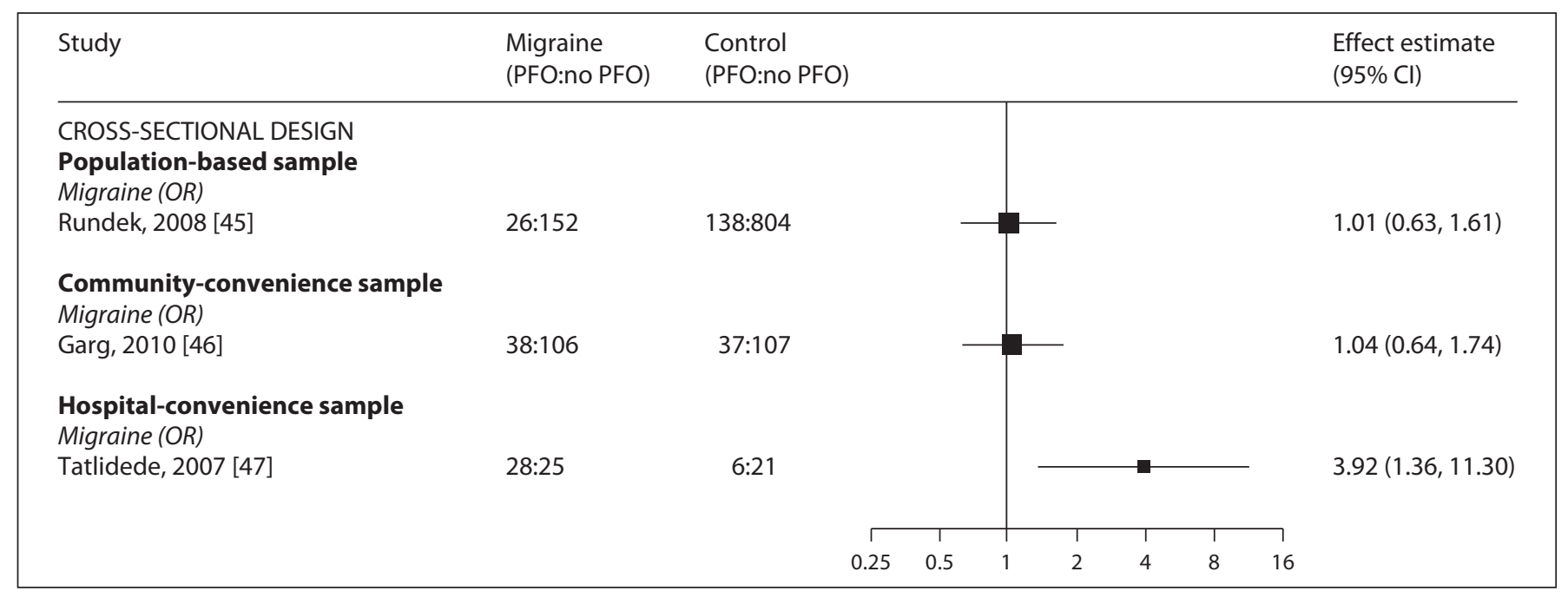

Fig. 4. Meta-analysis of the reported associations between PFO and migraine (by study design and sampling frame). Forest plot showing results of meta-analysis. Studies are grouped by design and sampling frame. Black squares are proportional to the study size, lines represent $95 \%$ confidence intervals.

\section{Strengths and Limitations}

This is the first review on this topic to stratify analyses on methodological grounds, which may explain why our conclusions differ from earlier meta-analyses. In applying a consistent approach to article selection and critical appraisal, we have been able to assess the evidence systematically across the three relationships. Our approach to meta-analysis has had the advantage of yielding low statistical measures of heterogeneity $\left(\mathrm{I}^{2}\right)$. While there are other procedures for addressing heterogeneity [53], our method has sound face validity. By identifying the observational studies at least risk of bias, we base our conclusions on the most epidemiologically applicable data.

For studies of migraine and ischemic stroke, there was inconsistency in controlling for possible confounders, in particular atrial fibrillation. Accordingly, the one prospective study to report a positive association (the WHS) should be considered with caution in this light.

The two population-based prospective studies of PFO and first-ever stroke risk had very similar results and did not demonstrate an association. It is possible that longer follow-up might have detected a small contribution of PFO to ischemic stroke risk. However, given the age-related incidence of more well-recognized risk factors for ischemic stroke, the power to detect an attributable risk from PFO probably diminishes with time. The populationbased case-control studies were in agreement, though the findings from Roijer et al. [34] are problematic because the age matching was unsuccessful, with controls being younger. In addition, although 'major potential cardioembolic sources' were excluded, a higher frequency of atrial fibrillation was reported in the cases. Despite these possible biases, the overall conclusions are acceptable in the context of the other population-based studies.

The only population-based data on the association between migraine and PFO assessed migraine in those reporting a past history of headache during a screening interview. Given the mean age of the participants (69 years), it has been suggested that recall bias may have caused an underestimation of migraine history, though the reported prevalence of migraine is consistent with other estimates from the general population [45]. Finally, because the pooled results from population-based studies did not demonstrate any clear associations, it was not possible to examine for any potential interactions or effect modifiers.

There are three main reasons that population-based observational studies may consistently report no association between migraine, PFO and cryptogenic stroke. Firstly, any misclassification of exposure status may bias any true association towards the null. In particular, studies employing TTE may have not detected PFO as reliably as more sensitive methods. Secondly, population-based studies may themselves been underpowered to detect the population-attributable fraction for stroke from PFO. Thirdly, the null hypothesis that PFO is not associated with stroke or migraine in unselected populations cannot 
be rejected. Therefore, there are general implications for trials considering PFO closure in terms of how to assess PFO, which subpopulations to sample and the sample size required to demonstrate a modifiable effect.

\section{Relationship to Other Meta-Analyses}

Previous meta-analyses have separately examined the relationships reviewed here. With regard to migraine and ischemic stroke, two recent systematic reviews have been conducted $[13,54]$. The eligibility criteria in these reviews did not specifically focus on cryptogenic stroke and included a larger number of studies. One review pooled with equal weighting - evidence across cohort (HR) and case-control studies (OR), finding an association measure of 2.2 (95\% CI 1.5-3.0) [13]. The other meta-analysis adopted similar methods but included a separate analysis restricted to studies at low risk of bias as determined by the authors (fewer than three 'poor' scores in different areas of the study design), in essence assigning an overall score for quality [54]. However, even in the analysis restricted to high-quality studies, the statistical heterogeneity was still sufficiently high to require a random-effects meta-analysis $\left(\mathrm{I}^{2}=68 \%\right)$. Because this in effect combines studies across different populations, it is no longer clear to which population the pooled estimate then applies. Assigning an overall quality score does not in itself address the biases within individual studies. We avoided this by stratifying our analyses where risk of bias due to study design and population sampling is likely to be similar across studies.

Two systematic reviews on the relationship between PFO and cryptogenic ischemic stroke have been published $[14,55]$. Both of these only examined case-control studies, thus do not account for evidence derived from prospective studies, and their results are consequently less conservative than ours, where the $\mathrm{PFO}$-stroke association was estimated as OR of 3.0 (95\% CI 2.0-4.3) for studies of PFO in cryptogenic stroke compared to nonstroke controls [55]. For the PFO-migraine association, another meta-analysis demonstrated an OR of 2.5 (95\% CI 2.0-3.1; PFO in migraineurs) and an OR of 5.1 (95\% CI 4.7-5.6; migraine in PFO patients) [15], though the systematic review predated the NOMAS report and also acknowledged that publication bias was likely. Two abstracts await full publication but appear to report associations in population-based samples. The Genetic Epidemiology of Migraine (GEM) study found migraine and PFO to be related only where PFO was also associated with an atrial septal aneurysm [48]. CAMERA is a MRI substudy of GEM, reporting a significant association in migraine with aura and PFO (OR 2.1; 95\% CI 1.1-3.9) [49]. However, it is unlikely that pooling the preliminary result with the NOMAS data would substantially alter these conclusions given that NOMAS is a much larger study.

\section{Implications for Randomized Trials}

The findings of this systematic review have implications for trials of PFO closure. If the underlying association is weaker than previously recognized (or non-existent), detecting a treatment effect may require enormous sample sizes (or may be impossible). However, if randomized trials demonstrate a treatment effect, this would provide evidence not only for an association between PFO and ischemic stroke or migraine, but one that is causal.

Our findings may account for the results of the CLOSURE trial [12]. The trial had an event rate (TIA and stroke) of $6 \%$ in the control arm and $2 \%$ in the closure arm. Also considering adverse effects of treatment, there were 7.7 and $5.9 \%$ events in the control and intervention groups, respectively $(p=0.30)$. Regardless of the concerns surrounding peri-procedural atrial fibrillation in this and other cohorts [56], one interpretation of the trial is that the underlying association is too small to be modified by an intervention with this efficacy.

The Migraine Intervention With STARFlex Technology (MIST) trial is the only double-blinded sham-controlled intervention trial in patients with refractory migraine with aura [11]. Though questions remain in respect of the possibility that interatrial shunts were not completely closed $[57,58]$, the reported data suggest no benefit of PFO closure on migraine. It has been proposed that MIST participants were not representative of those in whom treatment benefit was observed in uncontrolled trials (i.e. those migraineurs spontaneously improving after PFO closure for cryptogenic stroke) [59]. This observation is supported by the community-based studies finding no association between migraine and PFO in stroke-free populations identified in this review.

\section{Conclusions}

Our findings do not support an association between PFO in patients with cryptogenic ischemic stroke. Because the weak association between PFO and ischemic stroke in methodologically rigorous studies questions the causal role of PFO, randomized controlled trials of PFO closure constitute an essential test of the causal relationship. However, the weakness of the association in observational epidemiological studies, as well as the effective- 
ness of antithrombotic drugs in the secondary prevention of ischemic stroke [60], means that ongoing and future trials of PFO closure will need to be very large. PFO closure may be more effective in subgroups with a stronger association with ischemic stroke (and therefore at highest risk of future cardioembolism), possibly in persons with very large PFO shunts [32] or PFO associated with atrial septal aneurysm [48].

\section{Acknowledgement}

D.D. is funded by a Wellcome research training fellowship. J.G. is sponsored by a joint MRC/GlaxoSmithKline industrial CASE studentship. P.W. is supported by a non-clinical PhD studentship from the British Heart Foundation. B.S. is funded by the
Joint European Post-Doctoral Programme: The European Research Area in Ageing (ERA-AGE) Network FLARE Programme. R.A.-S.S. was funded by a UK Medical Research Council clinician scientist fellowship.

\section{Supporting Information}

Study characteristics of all included studies are given in full, along with referenced PRISMA flowchart detailing excluded studies. The MOOSE checklist is also submitted.

\section{Disclosure Statement}

The authors have no conflict of interest to declare.

\section{References}

1 Guercini F, Acciarresi M, Agnelli G, Paciaroni M: Cryptogenic stroke: time to determine aetiology. J Thromb Haemost 2008;6:549-554.

-2 Sacco RL, Adams R, Albers G, Alberts MJ, Benavente O, Furie K, Goldstein LB, Gorelick P, Halperin J, Harbaugh R, Johnston SC, Katzan I, Kelly-Hayes M, Kenton EJ, Marks M, Schwamm LH, Tomsick T: Guidelines for prevention of stroke in patients with ischemic stroke or transient ischemic attack: a statement for healthcare professionals from the American Heart Association/American Stroke Association Council on Stroke: cosponsored by the Council on Cardiovascular Radiology and Intervention: the American Academy of Neurology affirms the value of this guideline. Stroke 2006;37:577-617.

- 3 Goldstein LB, Adams R, Alberts MJ, Appel LJ, Brass LM, Bushnell CD, Culebras A, Degraba TJ, Gorelick PB, Guyton JR, Hart RG, Howard G, Kelly-Hayes M, Nixon JV, Sacco RL: Primary prevention of ischemic stroke: a guideline from the American Heart Association/American Stroke Association Stroke Council: cosponsored by the Atherosclerotic Peripheral Vascular Disease Interdisciplinary Working Group; Cardiovascular Nursing Council; Clinical Cardiology Council; Nutrition, Physical Activity, and Metabolism Council; and the Quality of Care and Outcomes Research Interdisciplinary Working Group: the American Academy of Neurology affirms the value of this guideline. Stroke 2006;37:1583-1633.

4 Windecker S, Wahl A, Chatterjee T, Garachemani A, Eberli FR, Seiler C, Meier B: Percutaneous closure of patent foramen ovale in patients with paradoxical embolism: long-term risk of recurrent thromboembolic events. Circulation 2000;101:893-898.
5 Bridges ND, Hellenbrand W, Latson L, Filiano J, Newburger JW, Lock JE: Transcatheter closure of patent foramen ovale after presumed paradoxical embolism. Circulation 1992;86:1902-1908.

-6 Martin F, Sanchez PL, Doherty E, ColonHernandez PJ, Delgado G, Inglessis I, Scott N, Hung J, King ME, Buonanno F, Demirjian Z, de Moor M, Palacios IF: Percutaneous transcatheter closure of patent foramen ovale in patients with paradoxical embolism. Circulation 2002;106:1121-1126.

7 Wilmshurst PT, Nightingale S, Walsh KP, Morrison WL: Effect on migraine of closure of cardiac right-to-left shunts to prevent recurrence of decompression illness or stroke or for haemodynamic reasons. Lancet 2000; 356:1648-1651.

8 Azarbal B, Tobis J, Suh W, Chan V, Dao C, Gaster R: Association of interatrial shunts and migraine headaches: impact of transcatheter closure. J Am Coll Cardiol 2005;45: 489-492.

-9 Reisman M, Christofferson RD, Jesurum J, Olsen JV, Spencer MP, Krabill KA, Diehl L, Aurora S, Gray WA: Migraine headache relief after transcatheter closure of patent foramen ovale. J Am Coll Cardiol 2005;45:493-495.

10 Schwerzmann M, Wiher S, Nedeltchev K, Mattle HP, Wahl A, Seiler C, Meier B, Windecker S: Percutaneous closure of patent foramen ovale reduces the frequency of migraine attacks. Neurology 2004;62:13991401.
11 Dowson A, Mullen MJ, Peatfield R, Muir K, Khan AA, Wells C, Lipscombe SL, Rees T, De Giovanni JV, Morrison WL, Hildick-Smith D, Elrington G, Hillis WS, Malik IS, Rickards A: Migraine Intervention with STARFlex Technology (MIST) trial: a prospective, multicenter, double-blind, shamcontrolled trial to evaluate the effectiveness of patent foramen ovale closure with STARFlex septal repair implant to resolve refractory migraine headache. Circulation 2008;117:1397-1404.

12 Furlan AJ, Reisman M, Massaro J, Mauri L, Adams H, Albers GW, Felberg R, Herrmann H, Kar S, Landzberg M, Raizner A, Wechsler L: Closure or medical therapy for cryptogenic stroke with patent foramen ovale. N Engl J Med 2012;366:991-999.

13 Schurks M, Rist PM, Bigal ME, Buring JE, Lipton RB, Kurth T: Migraine and cardiovascular disease: systematic review and meta-analysis. BMJ 2009;339:b3914.

14 Alsheikh-Ali AA, Thaler DE, Kent DM: Patent foramen ovale in cryptogenic stroke: incidental or pathogenic? Stroke 2009;40: 2349-2355.

-15 Schwedt TJ, Demaerschalk BM, Dodick DW: Patent foramen ovale and migraine: a quantitative systematic review. Cephalalgia 2008; 28:531-540.

16 Egger M, Schneider M, Davey Smith G: Spurious precision? Meta-analysis of observational studies. BMJ 1998;316:140-144.

17 Stroup DF, Berlin JA, Morton SC, Olkin I, Williamson GD, Rennie D, Moher D, Becker BJ, Sipe TA, Thacker SB: Meta-analysis of observational studies in epidemiology: a proposal for reporting. Meta-analysis Of Observational Studies in Epidemiology (MOOSE) group. JAMA 2000;283:2008-2012. 
18 Headache Classification Subcommittee of the International Headache Society: The International Classification of Headache Disorders: 2nd edition. Cephalalgia 2004; 24(suppl 1):9-160.

19 Classification and diagnostic criteria for headache disorders, cranial neuralgias and facial pain. Headache Classification Committee of the International Headache Society. Cephalalgia 1988;8(suppl 7):1-96.

20 Wells GA, Shea B, O'Connell D, Peterson J, Welch V, Losos M, Tugwell P: The Newcastle-Ottawa Scale (NOS) for assessing the quality of nonrandomised studies in metaanalyses. http://www.Ohri.Ca/programs/ clinical_epidemiology/oxford.Asp (accessed September 9, 2012).

-21 Kurth T, Gaziano JM, Cook NR, Logroscino G, Diener HC, Buring JE: Migraine and risk of cardiovascular disease in women. JAMA 2006;296:283-291.

-22 MacClellan LR, Giles W, Cole J, Wozniak M, Stern B, Mitchell BD, Kittner SJ: Probable migraine with visual aura and risk of ischemic stroke: The stroke prevention in young women study. Stroke 2007;38:2438-2445.

23 Schwaag S, Nabavi DG, Frese A, Husstedt IW, Evers S: The association between migraine and juvenile stroke: a case-control study. Headache 2003;43:90-95.

24 Carolei A, Marini C, De Matteis G: History of migraine and risk of cerebral ischaemia in young adults. The Italian National Research Council Study Group on Stroke in the Young. Lancet 1996;347:1503-1506.

-25 Tzourio C, Tehindrazanarivelo A, Iglesias S, Alperovitch A, Chedru F, d'Anglejan-Chatillon J, Bousser MG: Case-control study of migraine and risk of ischaemic stroke in young women. BMJ 1995;310:830-833.

-26 Tzourio C, Iglesias S, Hubert JB, Visy JM, Alperovitch A, Tehindrazanarivelo A, Biousse V, Woimant F, Bousser MG: Migraine and risk of ischaemic stroke: a case-control study. BMJ 1993;307:289-292.

$\checkmark 27$ Chang CL, Donaghy M, Poulter N: Migraine and stroke in young women: Case-control study. The World Health Organisation Collaborative Study of Cardiovascular Disease and Steroid Hormone Contraception. BMJ 1999;318:13-18.

-28 Barinagarrementeria F, Gonzalez-Duarte A, Miranda L, Cantu C: Cerebral infarction in young women: analysis of 130 cases. Eur Neurol 1998;40:228-233.

29 Henrich JB, Horwitz RI: A controlled study of ischemic stroke risk in migraine patients. J Clin Epidemiol 1989;42:773-780.

30 Meissner I, Khandheria BK, Heit JA, Petty GW, Sheps SG, Schwartz GL, Whisnant JP, Wiebers DO, Covalt JL, Petterson TM, Christianson TJ, Agmon Y: Patent foramen ovale: innocent or guilty? Evidence from a prospective population-based study. J Am Coll Cardiol 2006;47:440-445.
31 Di Tullio MR, Sacco RL, Sciacca RR, Jin Z, Homma S: Patent foramen ovale and the risk of ischemic stroke in a multiethnic population. J Am Coll Cardiol 2007;49:797-802.

- 32 Sastry S, Riding G, Morris J, Taberner D, Cherry N, Heagerty A, McCollum C: Young Adult Myocardial Infarction and Ischemic Stroke: the role of paradoxical embolism and thrombophilia (The YAMIS Study). J Am Coll Cardiol 2006;48:686-691.

33 Petty GW, Khandheria BK, Meissner I, Whisnant JP, Rocca WA, Christianson TJ, Sicks JD, O'Fallon WM, McClelland RL, Wiebers DO: Population-based study of the relationship between patent foramen ovale and cerebrovascular ischemic events. Mayo Clin Proc 2006;81:602-608.

34 Roijer A, Lindgren A, Algotsson L, Norrving B, Olsson B, Eskilsson J: Cardiac changes in stroke patients and controls evaluated with transoesophageal echocardiography. Scand Cardiovasc J 1997;31:329-337.

35 Serena J, Segura T, Perez-Ayuso MJ, Bassaganyas J, Molins A, Davalos A: The need to quantify right-to-left shunt in acute ischemic stroke: a case-control study. Stroke 1998;29: 1322-1328.

36 Jones EF, Calafiore P, Donnan GA, Tonkin AM: Evidence that patent foramen ovale is not a risk factor for cerebral ischemia in the elderly. Am J Cardiol 1994;74:596-599.

37 Mattioli AV, Bonetti L, Aquilina M, Oldani A, Longhini C, Mattioli G: Association between atrial septal aneurysm and patent foramen ovale in young patients with recent stroke and normal carotid arteries. Cerebrovasc Dis 2003;15:4-10.

- 38 Cabanes L, Mas JL, Cohen A, Amarenco P, Cabanes PA, Oubary P, Chedru F, Guerin F, Bousser MG, de Recondo J: Atrial septal aneurysm and patent foramen ovale as risk factors for cryptogenic stroke in patients less than 55 years of age. A study using transesophageal echocardiography. Stroke 1993; 24:1865-1873.

39 Schuchlenz HW, Weihs W, Horner S, Quehenberger F: The association between the diameter of a patent foramen ovale and the risk of embolic cerebrovascular events. Am J Med 2000;109:456-462.

-40 Cerrato P, Imperiale D, Priano L, Mangiardi L, Morello M, Marson AM, Carra F, Barberis G, Bergamasco B: Transoesophageal echocardiography in patients without arterial and major cardiac sources of embolism: difference between stroke subtypes. Cerebrovasc Dis 2002;13:174-183.

41 Di Tullio M, Sacco RL, Gopal A, Mohr JP, Homma S: Patent foramen ovale as a risk factor for cryptogenic stroke. Ann Intern Med 1992;117:461-465.

42 Force M, Massabuau P, Larrue V: Prevalence of atrial septal abnormalities in older patients with cryptogenic ischemic stroke or transient ischemic attack. Clin Neurol Neurosurg 2008;110:779-783.
43 Handke M, Harloff A, Olschewski M, Hetzel A, Geibel A: Patent foramen ovale and cryptogenic stroke in older patients. N Engl J Med 2007;357:2262-2268.

-44 Negrao EM, Brandi IV, Nunes SV, Tavora DG, Nakayama M, Beraldo PS: Patent foramen ovale and ischemic stroke in young people: statistical association or causal relation? Arq Bras Cardiol 2007;88:514-520.

45 Rundek T, Elkind MS, Di Tullio MR, Carrera E, Jin Z, Sacco RL, Homma S: Patent foramen ovale and migraine: a cross-sectional study from the Northern Manhattan Study (NOMAS). Circulation 2008;118:1419-1424.

46 Garg P, Servoss SJ, Wu JC, Bajwa ZH, Selim $\mathrm{MH}$, Dineen A, Kuntz RE, Cook EF, Mauri L: Lack of association between migraine headache and patent foramen ovale: results of a case-control study. Circulation 2010;121: 1406-1412.

47 Tatlidede AD, Oflazoglu B, Celik SE, Anadol U, Forta H: Prevalence of patent foramen ovale in patients with migraine. Agri 2007; 19:39-42.

48 De Heij AH, Luermans JGLM, Thijs V, Schonewille W, Plokker HWM, Budts W, Post MC: Patent foramen ovale with atrial septal aneurysm is a strong independent predictor for migraine with aura: a large prospective observational study. Eur Heart J 2010;31:865

49 Koppen H, Palm-Meinders IH, Mess WH, Keunen RW, Terwindt GM, Launer LJ, Van Buchem MA, Ferrari MD, Kruit MC: Population-based evidence for an association between migraine and right-to-left shunt (PFO). Cephalalgia 2009;29:1352.

50 Conen D, Chae CU, Glynn RJ, Tedrow UB, Everett BM, Buring JE, Albert CM: Risk of death and cardiovascular events in initially healthy women with new-onset atrial fibrillation. JAMA 2011;305:2080-2087.

51 Mas JL, Arquizan C, Lamy C, Zuber M, Cabanes L, Derumeaux G, Coste J: Recurrent cerebrovascular events associated with patent foramen ovale, atrial septal aneurysm, or both. N Engl J Med 2001;345:1740-1746.

52 Feurer R, Sadikovic S, Sepp D, Esposito L, Schleef M, Bockelbrink A, Schwarze J, Hemmer B, Sander D, Poppert H: Patent foramen ovale is not associated with an increased risk of stroke recurrence. Eur J Neurol 2010;17: 1339-1345.

53 Ioannidis JP, Patsopoulos NA, Rothstein HR: Reasons or excuses for avoiding metaanalysis in forest plots. BMJ 2008;336:14131415.

54 Spector JT, Kahn SR, Jones MR, Jayakumar M, Dalal D, Nazarian S: Migraine headache and ischemic stroke risk: an updated metaanalysis. Am J Med 2010;123:612-624.

55 Overell JR, Bone I, Lees KR: Interatrial septal abnormalities and stroke: a meta-analysis of case-control studies. Neurology 2000;55: 1172-1179. 
-56 Wahl A, Meier B, Haxel B, Nedeltchev K, Arnold M, Eicher E, Sturzenegger M, Seiler C, Mattle HP, Windecker S: Prognosis after percutaneous closure of patent foramen ovale for paradoxical embolism. Neurology 2001; 57:1330-1332.

57 Carroll JD: Migraine Intervention with STARFlex Technology trial: a controversial trial of migraine and patent foramen ovale closure. Circulation 2008;117:1358-1360.

58 Gornall J: A very public break-up. BMJ 2010; 340:c110.

59 Gersony WM, Gersony DR: Migraine headache and the patent foramen ovale. Circulation 2010;121:1377-1378.
60 Rothwell PM, Algra A, Amarenco P: Medical treatment in acute and long-term secondary prevention after transient ischaemic attack and ischaemic stroke. Lancet 2011;377:16811692.

61 De Castro S, Cartoni D, Fiorelli M, Rasura M, Anzini A, Zanette EM, Beccia M, Colonnese C, Fedele F, Fieschi C, Pandian NG: Morphological and functional characteristics of patent foramen ovale and their embolic implications. Stroke 2000;31:2407-2413.

62 Serena J, Marti-Fabregas J, Santamarina E, Rodriguez JJ, Perez-Ayuso MJ, Masjuan J, Segura T, Gallego J, Davalos A: Recurrent stroke and massive right-to-left shunt: Results from the prospective Spanish multicenter (CODICIA) study. Stroke 2008;39: 3131-3136.
63 Comess KA, DeRook FA, Beach KW, Lytle NJ, Golby AJ, Albers GW: Transesophageal echocardiography and carotid ultrasound in patients with cerebral ischemia: prevalence of findings and recurrent stroke risk. J Am Coll Cardiol 1994;23:1598-1603.

64 Cujec B, Mainra R, Jonhson DH: Prevention of recurrent cerebral ischemic events in patients with patent foramen ovale and cryptogenic strokes or transient ischemic attacks. Can J Cardiol 1999;15:57-64.

65 Chen WJ, Lin SL, Chen JJ, Lien WP: The frequency of patent foramen ovale in patients with ischemic stroke: a transesophageal echocardiographic study. J Formos Med Assoc 1991;90:744-748. 